\title{
Beat Diabetes: Are We Ready
}

\section{Kedar Mehta* and Paragkumar Chavda}

Department of Community Medicine, GMERS Medical college, Gotri, Vadodara, Gujarat, India

Diabetes is a serious and silent chronic non communicable disease in which the pancreas of the body does not produce the blood sugar regulating insulin hormone. It has become an important public health problem as there has been alarming rise in the number of cases since last few decades.

As per the report by World Health Organization (WHO), there is a global estimate of 422 million adults living with diabetes in 2014 and 1.5 million deaths due to diabetes since 2012 [1]. India is expected to become capital of diabetes with an estimate of 109 million diabetic individuals by 2035 as per the report of Indian Heart Association [2]. Nearly $7 \%$ of Indian adult population (62 million) is estimated to be affected by diabetes [3]. This is just the tip of the iceberg. Iceberg phenomenon of disease suggests that the submerged portion of the iceberg would be much bigger than the tip of the iceberg. In this case the number of people living with diabetes yet undiagnosed/undetected or asymptomatic or untreated is very high. This is one of the important challenges to meet the latest World Health Day Theme of 2016 "Beat the diabetes". There is a need to focus on prediabetes condition also in which individuals have high glucose level but not enough to classify as diabetes. They have high risk of developing type 2 diabetes. This needs to be addressed by early diagnosis of diabetes by early detection of its risk factors by the use of simple yet effective tools like Diabetes risk score assessment tool developed by Madras Diabetic Research
Foundation [4]. There is an urgent need for availability of some basic diagnostic facility like blood sugar testing at almost all primary health care institutions. Also there is a need for primary prevention addressing the risk factors specially focusing on the modifiable ones. The focus on diet has been around but the same needs to be given to physical activity also. Also there is a need to target the health promotion efforts at audience at a younger age. Strategy of involving schools in such efforts can be explored.

Govt. of India has already launched the National Programme for Prevention and Control of Cancer, Diabetes, Cardiovascular Disease and Stroke (NPCDCS) to control and prevent non communicable diseases in India. But still it has been in pilot phase. So India has started showing readiness to beat against diabetes but still a long way forward to achieve its goal.

\section{References}

1. World Health Organization (WHO) (2016) Global Report on Diabetes.

2. http://indianheartassociation.org/why-indians-why-south-asians/

3. Joshi SR (2012) Type 2 diabetes in Asian Indians. Clin Lab Med 32: 207 -216.

4. Mohan V, Deepa R, Deepa M, Somannavar S, Datta MA (2005) Simplified indian diabetes risk score for screening for undiagnosed diabetic subjects. J Assoc Physicians India 53: 759-763.
*Corresponding author: Kedar Mehta, Department of Community Medicine, GMERS Medical college, Gotri, Vadodara, Gujarat, India, Tel: +91 9879036835 E-mail: kedar_mehta@yahoo.co.in

Received May 05, 2016; Accepted May 06, 2016 ; Published May 12, 2016

Citation: Mehta K, Chavda P (2016) Beat Diabetes: Are We Ready Gen Med (Los Angel) 4: e108. doi:10.4172/2327-5146.1000e108

Copyright: ( 2016 Mehta K, et al. This is an open-access article distributed under the terms of the Creative Commons Attribution License, which permits unrestricted use, distribution, and reproduction in any medium, provided the original author and source are credited. 